\title{
A governança de cadeias de suprimentos: uma análise a partir da teoria da agência e stewardship theory
}

\author{
The governance of supply chains: an analysis base on the agency theory and \\ the stewardship theory
}

\author{
Alecsandro Roberto Lemos Francisco ${ }^{1}$ \\ Daniela Siqueira Colet ${ }^{2}$ \\ Douglas Wegner ${ }^{3}$
}

\begin{abstract}
Resumo
O objetivo desta pesquisa consiste em analisar como três condições de troca - oportunismo, poder e risco - explicam a utilização de elementos de governança em cadeias de suprimento. Como bases teóricas, foram utilizadas a teoria da agência e a stewardship theory, que apresentam elementos de governança utilizados em cadeia de suprimentos. Para atender ao objetivo proposto, desenvolveu-se uma pesquisa qualitativa explanatória, por meio de um estudo de caso único com unidades incorporadas. As unidades de análise são as relações diádicas de uma cadeia de suprimentos de uma organização multinacional que atua no mercado brasileiro de elevadores. Os resultados desta pesquisa apontam que as condições de troca explicam a utilização de elementos de governança, por meio de cinco razões: a) a existência de condições de troca; b) as origens das condições de troca; c) a decisão do gestor em utilizar elementos de governança; d) a influência pessoal sobre a decisão do gestor; e e) a decisão conjunta dos envolvidos na relação diádica em utilizar elementos de governança. Entre as contribuições teóricas deste estudo, infere-se a influência de ordem pessoal na decisão de utilização de elementos de governança e, entre as contribuições gerenciais, sugere-se a criação de uma diretriz corporativa para a cadeia de suprimentos da organização.
\end{abstract}

Palavras-chave: Cadeia de suprimentos. Governança. Condições de troca.

\begin{abstract}
The objective of this research is to analyze how three exchange conditions - opportunism, power and risk - explain the use of governance elements in supply chains. The study was supported by the agency theory and stewardship theory, which present governance elements that can be used in supply chains. In order to meet the proposed objective, a qualitative explanatory research was developed, through a single case study with built-in units. The units of analysis are the dyadic relationships of a multinational organization, which operates in the Brazilian elevator market. The results show that the exchange conditions of each relationship explain the use of governance elements, through five reasons: a) the existence of exchange conditions; b) the origins of the exchangeconditions; c) the manager's decision to use governance elements; d) the manager's personal influence on the decision; e) the joint decision of those involved in the dyadic relationship in using governance elements. As a theoretical contribution this study highlights the personal influence of managers decisions on the governance of dyadic relationships. As a managerial contribution the study suggests the creation of corporate guidelines for the governance of supply chain relationships.
\end{abstract}

Keywords: Supply chain. Governance. Conditions of exchange.

\section{Introdução}

A cadeia de suprimentos é um campo de estudos amplo, que desperta o interesse de pesquisadores e gestores em razão da sua importância estratégica para a competitividade das organizações e pelo alto volume de recursos técnicos, financeiros e humanos investidos na sua gestão (LAMBERT; ENZ, 2017). Nas

Mestre em Administração pela Universidade do Vale do Rio dos Sinos. Afiliação: Unisinos University. Brasil. Lattes: http://lattes.cnpq. br/2959431710024436 Email: alecsandro.francisco@gmail.com

2 Mestre em Administração pela Universidade de Passo Fundo. Afiliação: University of Passo Fundo. Brasil. Lattes: http://lattes.cnpq. br/6583656208588651 Email: danicolet@upf.br

Doutor em Administração pela Universidade Federal do Rio Grande do Sul. Afiliação: Unisinos University. Brasil. Lattes: http://lattes.cnpq. br/1623033647698028 Orcid: http://orcid.org/0000-0001-8634-5971 Email: douglaswegner@hotmail.com 
últimas décadas, as organizações vêm concentrando suas atividades nas competências centrais e repassando aos fornecedores $\mathrm{o}$ atendimento de atividades de suporte às atividades principais, tais como distribuição, vendas e abastecimento de materiais auxiliares (TEIXEIRA; LACERDA, 2010). Tamanha importância pode explicar o interesse da academia em analisar o que ocorre nas relações interorganizacionais que compõem uma cadeia de suprimentos.

A governança de uma cadeia de suprimentos atua nos laços relacionais existentes entre duas ou mais organizações, e o nível de interação entre essas organizações depende dessa governança. Por isso, diferentes formas de governança da cadeia de suprimentos podem influenciar o resultado de uma organização (BURKERT, IVENS e SHAN, 2012). Condições de troca é o termo escolhido para representar o grupo de fatores que atuam sobre as relações diádicas, e que inserem certo grau de incerteza ou exposição desfavorável (POPPO e ZENGER, 2002). Tendo em vista que cada relação fornecedor-cliente é caracterizada por condições específicas de troca, pode não ser assertivo utilizar elementos de governança de forma padronizada sobre todos os relacionamentos diádicos que compõem a cadeia de suprimentos. Cada organização precisa definir critérios para identificar os elementos de governança mais adequados a cada tipo de relacionamento. Reconhecer as condições de troca, suas influências e o impacto que geram na cadeia é primordial para a definição dos elementos de governança aplicáveis a cada caso.

Nesse sentido, emerge a necessidade de elementos de governança para a cadeia de suprimentos (WIENGARTEN, PAGELL e FYNES, 2013; WATHNE e HEIDE, 2004; HUANG, CHENG, e TSENG, 2014). Mais que isso, os elementos precisam ser compatíveis com os diferentes relacionamentos diádicos e as condições de troca que os influenciam. Ainda é preciso, entretanto, avançar na compreensão de aspectos específicos sobre a governança da cadeia de suprimentos. Zander, Trang e Kolbe (2016), por exemplo, argumentam que existem poucos resultados de estudos empíricos sobre a governança de cadeias de suprimentos orientados para a causa ambiental. Dolci, Maçada e Grant (2015) estudam o apoio de investimentos em TI (Tecnologia da Informação) sobre as governanças relacional e transacional de cadeias de suprimentos brasileiras. Tais estudos exemplificam a dimensão desse tema e justificam a busca por melhor compreensão. Nesse contexto, o objetivo deste estudo consiste em analisar como três condições de troca - oportunismo, poder e risco - explicam a utilização de elementos de governança em cadeias de suprimentos.

No campo teórico, o estudo contribui especialmente para o avanço dos estudos sobre governança em cadeia de suprimentos e para a compreensão do impacto da interferência humana nas decisões de uso dos elementos de governança diante das condições de troca. No campo gerencial, os resultados oferecem orientações para organizações que necessitam aperfeiçoar a governança da sua cadeia de suprimentos.

Após esta introdução, o artigo contempla a abordagem teórica, que fornece suporte para a pesquisa empírica e auxilia para uma melhor compreensão sobre a temática deste estudo. Na seção seguinte, apresentam-se os procedimentos metodológicos que orientaram os caminhos seguidos para realização da pesquisa. Por fim, os dados são analisados e interpretados para, posteriormente, as considerações finais serem apresentadas.

\section{Referencial Teórico}

\subsection{Cadeia de suprimentos e governança nas relações interorganizacionais}

A cadeia de suprimentos pode ser compreendida como uma rede de relacionamentos diádicos que envolve sucessivas transformações com agregação de valor e estágios intermediários (COX, SANDERSON; WATSON, 2001; LAMBERT; ENZ, 2017). Para Benton (2005), um produto é entregue ao cliente final através de uma cadeia de suprimentos, que é formada por fornecedores, fabricantes e distribuidores. A força da cadeia de suprimentos está na interdependência entre seus membros, e é medida em seu elo de relacionamento mais fraco. Tal mensuração é demonstrada pelo autor ao relacionar performance e satisfação dos fornecedores como variáveis dependentes de relacionamento influenciado por diferentes tipos de poder aplicados a cadeia de suprimentos.

Na maioria dos estudos, a cadeia de suprimentos é definida como uma rede de organizações orientadas para objetivos de ordem comum (THOMÉ, SCAVARDA, CERYNO e KLINGEBIEL, 2014; DEFEE; ESPER; 
MOLLENKOPF, 2009; HUO; ZHAO; LAI, 2014). Também se destaca o caráter independente de cada organização, visto que a participação em uma cadeia de suprimentos não é uma obrigatoriedade, mas resultado de um acordo de relacionamento previamente realizado. Nesse contexto, encontra-se a conexão com a governança. Se uma cadeia de suprimentos é uma rede de relacionamentos finitos entre organizações independentes, que durante certo tempo atuam em prol de objetivos alinhados, é presumível que essa condição demande elementos de governança.

Hernández-Espallardo et al. (2010) conceituam a governança como um elemento de salvaguarda contra o risco de oportunismo. De forma complementar, argumentam que governança é a adoção de elementos híbridos que podem ser usados para proteger investimentos específicos sem a necessidade de uma completa verticalização do processo de produção. Para Gereffi, Humphrey e Sturgeon (2005), são cinco as tipologias possíveis de governança para a cadeia de suprimentos, a saber: mercado - identificada pelo baixo risco de troca de fonte de suprimento para a organização-focal; cadeia de valor modular - relação em que o fornecedor se responsabiliza pelo atendimento das especificações do produto do cliente, aplicando meios de produção e investimentos em prol da geração de valor para o cliente; cadeia de valor relacional representada por vínculos familiares, éticos ou laços de confiança fortalecidos ao longo do tempo; cadeia de valor cativa - caracterizada por alto nível de dependência do fornecedor em relação à organização-cliente; hierarquia - cadeia de suprimento formada pela verticalização dos processos produtivos acumulados na organização.

Provan e Kenis (2007) explicam a governança como a utilização de instituições e estruturas de autoridade e colaboração para alocar recursos, coordenar e controlar ações conjuntas em relações interorganizacionais. Os autores apresentam três formas distintas de governança: compartilhada, organização-líder e organização administrativa da rede. Dentre elas, destaca-se para este trabalho o conceito de governança por meio de organizaçãolíder. Em geral, os elementos de governança são determinados pela organização focal, uma vez que a razão de existir da cadeia de suprimentos é a comercialização dos produtos e serviços de propriedade da organização focal. Dessa forma, entende-se que a rede formada por uma cadeia de suprimentos demanda governança porque exige relacionamento, acompanhamento de decisões e verificações in loco que reforcem os vínculos que formam as relações diádicas (DYER, 1996). Na sequência, apresentam-se as teorias que dão sustentação ao estudo: teoria da agência e a stewardship theory, que evidenciam o impacto das motivações do ser humano nas relações interorganizacionais existentes na cadeia de suprimentos.

\subsection{Teoria da Agência}

A teoria da agência busca explicar o conflito de interesses que ocorre na relação principal-agente, partindo de alguns pressupostos de origem humana: oportunismo, racionalidade limitada e aversão ao risco (Eisenhardt, 1989). O Quadro 1 apresenta os pressupostos gerais da teoria da agência.

Quadro 1 - Visão geral da teoria da agência

\begin{tabular}{|l|l|}
\hline Ideia principal & $\begin{array}{l}\text { Relacionamento principal-agente deve refletir uma organização eficiente de } \\
\text { informação e custos de gerenciamento de riscos. }\end{array}$ \\
\hline Unidade de análise & Contratos entre principal e agente. \\
\hline Pressupostos humanos & $\begin{array}{l}\text { Oportunismo. } \\
\text { Racionalidade limitada. } \\
\text { Aversão ao risco. }\end{array}$ \\
\hline Pressupostos organizacionais & $\begin{array}{l}\text { Conflito de metas. } \\
\text { Eficiência como critério de efetividade. } \\
\text { Assimetria de informação entre principal e agente. }\end{array}$ \\
\hline Pressupostos informacionais & Informação vista como algo que pode ser comprado. \\
\hline Problemas de contratação & $\begin{array}{l}\text { Agência: dano moral e seleção adversa. } \\
\text { Compartilhamento de riscos. }\end{array}$ \\
\hline Problema prioritário & $\begin{array}{l}\text { Relacionamentos nos quais, principal e agente divergem em metas e } \\
\text { preferências de risco. }\end{array}$ \\
\hline
\end{tabular}

Fonte: Eisenhardt (1989), adaptado pelos autores. 
Os pressupostos humanos denotam a visão econômica do ser humano e suas motivações. Já os pressupostos organizacionais e informacionais podem ser entendidos como desdobramentos dos pressupostos humanos, porque são os resultados de decisões tomadas pelas pessoas que ocupam os papéis de agente e principal, que são executadas através dos processos organizacionais.

Para Eisenhardt (1989), os problemas de contratação introduzem dois conceitos importantes da teoria da agência que ocorrem em função da assimetria de informação, um dos pressupostos organizacionais. $O$ primeiro, dano moral, ocorre quando o agente percebe a incapacidade de compreensão do principal sobre seus atos. O segundo se refere à seleção adversa, que ocorre quando o principal contrata um agente sem verificar sua capacidade para o exercício da função. Essa incapacidade ou erro na interpretação das habilidades apresentadas pelo agente são razões que explicam tal falha. Numa cadeia de suprimentos, um exemplo seria firmar um contrato de serviços com uma empresa tecnicamente incapaz.

Complementarmente, a divergência de metas e diferentes preferências de riscos definem o problema prioritário da teoria da agência. Tais fontes de conflito geram o custo de agência, formado pela soma de três componentes (JENSEN EMECKLING, 1976). O primeiro consiste em despesas de monitoramento, que são gastos realizados pelo principal para controlar as ações do agente. O segundo componente trata das despesas de bonificação, pagas para o agente, como incentivo para mantê-lo focado nos interesses do principal. O terceiro é denominado de perdas residuais, que advêm da diferença entre os resultados possíveis de uma decisão tomada pelo agente. Na teoria da agência, as empresas de uma cadeia de suprimentos possuem interesses diferentes. A governança emerge como um conjunto de práticas para garantir o controle da organização focal, já os contratos fornecem garantias aos integrantes da cadeia de suprimentos, possibilitando a realização das atividades acordadas (DOLCl, 2013).

No Quadro 2 ilustra-se os elementos de governança dos estudos de autores e a relação dos elementos com as condições de troca de forma genérica para simplificar a compreensão do quadro. Destaca-se a recorrência dos conceitos abordados, bem como os vínculos que ocorrem entre eles. Um determinado elemento de governança pode ser utilizado diante de diferentes condições de troca, e, da mesma forma, uma condição de troca pode estar associada a diferentes elementos de governança.

Quadro 2 - Condições de troca e elementos de governança da teoria da agência

\begin{tabular}{|c|c|c|c|c|l|}
\hline \multirow{2}{*}{$\begin{array}{c}\text { Condições de } \\
\text { troca }\end{array}$} & \multicolumn{4}{|c|}{ Elementos de governança } & \multicolumn{1}{|c|}{ Autores } \\
\cline { 2 - 6 } Oportunismo & Confiança & Contratos & Controle & Incentivos & \multicolumn{1}{|c|}{} \\
\cline { 2 - 6 } & $\square$ & $\square$ & $\square$ & & Huang et al. (2014) \\
\cline { 2 - 6 } Poder & $\square$ & $\square$ & & & Storey et al. (2013) \\
\cline { 2 - 6 } Risco & & $\square$ & $\square$ & $\square$ & Morgan et al. (2007) \\
\cline { 2 - 6 } & & $\square$ & $\square$ & $\square$ & Müller e Gaudig, (2011) \\
\cline { 2 - 6 } & & $\square$ & $\square$ & $\square$ & Wiengarten et al. (2013) \\
\hline
\end{tabular}

Fonte: Desenvolvido pelos autores.

Portanto, a partir dos conceitos abordados na teoria da agência, quatro elementos de governança são identificados. A próxima seção apresenta a revisão da literatura sobre a stewardship theory, bem como a sua aplicação nos estudos ligados à governança da cadeia de suprimentos.

\subsection{A stewardship theory}

A stewardship theory evidencia o impacto das motivações do ser humano nas relações interorganizacionais existentes na cadeia de suprimentos. Essa teoria se distancia dos pressupostos da teoria da agência, porque se baseia em princípios psicológicos e sociológicos. São premissas comportamentais e motivacionais que conduzem a lógica dessa teoria (DAVIS, SCHOORMAN; DONALDSON, 1997).

Em seu estudo, Hernandez (2007) define stewardship como um conjunto de atitudes e comportamentos que colocam os melhores interesses em longo prazo de um grupo, à frente de metas pessoais, que servem 
apenas aos interesses individuais. Além disso, propõe as figuras do líder e seguidor como ícones similares às imagens do principal e do agente. Nesse contexto, os gestores não são motivados por metas individuais e preferem atuar como stewards, cujas motivações estão alinhadas aos objetivos da organização em que atuam (DAVIS, SCHOORMAN e DONALDSON, 1997).

Embora seu estudo enfoque uma crítica à visão econômica da teoria da agência, Ghoshal (2005) contribui para a formação da conceituação da stewardship theory. O autor argumenta que a governança pode focar nos interesses dos clientes, empregados, acionistas e das comunidades na qual organização está inserida, ao invés de concentrar proteção apenas aos interesses de acionistas. Hirsch et al. (1987) consolidam as bases de desenvolvimento da stewardship theory ao evidenciarem características inerentes à condição humana que ganhavam pouca atenção na lógica econômica e, consequentemente, também na teoria da agência. Além da explicação de natureza sociológica, a stewardship theory também é suportada pelo estudo das motivações do ser humano.

Davis, Schoorman e Donaldson, (1997) subdividem a motivação por meio de fatores extrínsecos e intrínsecos ao homem, direcionando o comportamento stewardship aos fatores intrínsecos. São exemplos as recompensas intangíveis, como oportunidades de crescimento, realizações profissionais e autorrealização. Os autores também citam a necessidade de ordem maior, numa alusão à pirâmide de Maslow, para apresentar outros fatores motivacionais, como liderança, autodeterminação, autonomia e senso de propósito.

Hernandez (2007) complementa sua visão sobre stewardship theory com um modelo teórico baseado em três amparos: relacional, contextual e motivacional. E, por meio desses amparos, apresenta confiança como um construto dessa teoria. O autor ainda argumenta que os amparos relacional e contextual são o resultado da interação do líder com seus seguidores. No nível interpessoal, o líder desenvolve o amparo relacional e, em nível institucional, o amparo contextual, que consequentemente viabilizam o amparo motivacional. Esse último pode ser definido como a capacidade do líder em desenvolver em seus seguidores sensos de autoeficiência e autoconfiança. Assim, os seguidores passam a acreditar em suas capacidades para desempenhar atividades de trabalho com habilidade.

Inicialmente, o modelo proposto por Hernandez (2012) apresenta os fatores estruturais da stewardship theory. Entre esses fatores, se encontram as práticas de gestão, liderança, políticas, procedimentos, sistemas e rotinas, divididos em duas categorias: sistemas de controle e sistemas de recompensa. Defendese que os fatores estruturais visam a promover a habilidade dos colaboradores para contribuir com os objetivos estratégicos e tomar decisões, bem como fazer parte de um modelo de governança que oriente o comportamento dos seus colaboradores para a conquista de benefícios coletivos. Especificamente, os sistemas de controle visam à colaboração nos atos de liderança e obtenção de resultados, o que habilita os colaboradores a compartilhar responsabilidade.

Outro ponto destacado na stewardship theory refere-se ao relacionamento. A análise realizada sobre mecanismos cognitivos e afetivos evidencia a busca por aproximação entre as partes, que visam estabelecer laços de colaboração e confiança (HERNANDEZ, 2012). Na cadeia de suprimentos, a stewardship theory postula que diferentes membros devem ser vistos como parceiros, com interesses que se harmonizam. Tal parceria é construída por meio de confiança e colaboração que se estabelecem pelos relacionamentos entre as organizações (DOLCl, 2013). O Quadro 3 apresenta um resumo dos elementos de governança que são suportados pelos conceitos estudados na stewardship theory.

Quadro 3 - Condições de troca e elementos de governança da stewardship theory

\begin{tabular}{|c|c|c|c|c|c|c|c|c|}
\hline \multirow{2}{*}{$\begin{array}{l}\text { Condições de } \\
\text { troca }\end{array}$} & \multicolumn{7}{|c|}{ Elementos de governança } & \multirow{2}{*}{ Autores } \\
\hline & Colaboração & Confiança & Contratos & Controle & Incentivos & Motivação & Relacionamento & \\
\hline \multirow[b]{4}{*}{ Oportunismo } & $\square$ & & $\square$ & & & & $\square$ & Luoet al. (2010) \\
\hline & $\square$ & & & & & & & Dolci (2013) \\
\hline & & $\square$ & $\square$ & $\square$ & $\square$ & & & Vosselmanet al. (2009) \\
\hline & & $\square$ & $\square$ & & & & $\square$ & Lee e Cavusgil (2006) \\
\hline \multirow{3}{*}{ Poder } & & & & $\square$ & & & & Heideet al. (2013) \\
\hline & & & & $\square$ & & & & Arnold et al. (2012) \\
\hline & & & $\square$ & & $\square$ & $\square$ & & Newton et al. (2013) \\
\hline
\end{tabular}

Fonte: Desenvolvido pelos autores. 
Assim, conclui-se esta revisão das teorias de base. Consolida-se que alguns elementos de governança são comuns às duas teorias analisadas, outros aparecem mais alinhados com os pressupostos da stewardship theory. A próxima seção apresenta outros conceitos necessários à compreensão do tema deste trabalho.

\subsection{Condições de troca e elementos de governança}

As relações diádicas na cadeia de suprimentos são influenciadas por condições de troca que exigem a utilização de elementos de governança que direcionem as relações para resultados positivos. Tais fatores interferem no ambiente das relações interorganizacionais da cadeia de suprimentos.

Ao todo, três fatores encontrados na teoria da agência e na stewardship theory caracterizam-se como condições de troca, isto é, fatores presentes em relações diádicas em uma cadeia de suprimentos e que podem influenciar a utilização de elementos de governança. As três condições de troca são retomadas e sintetizadas no Quadro 4.

Quadro 4 - Conceitos das condições de troca

\begin{tabular}{|l|l|l|}
\hline Condição de troca & Definição & Principais autores \\
\hline Oportunismo & $\begin{array}{l}\text { Satisfação do interesse próprio através de vantagem obtida } \\
\text { pela falta de informação da outra parte. }\end{array}$ & (Williamson, 1975) \\
\hline Poder & $\begin{array}{l}\text { É a combinação de elementos organizacionais, individuais e } \\
\text { relacionais coordenada para influenciar a outra parte. }\end{array}$ & (Meehan e Wright, 2012) \\
\hline Risco & $\begin{array}{l}\text { Configura-se como a exposição ao oportunismo, e as fontes } \\
\text { de risco em uma cadeia de suprimentos são: disponibilidade } \\
\text { de materiais, número de fornecedores, demanda, análise } \\
\text { make-or-buy, riscos de estoque e substituição de materiais. }\end{array}$ & $\begin{array}{l}\text { (Kraljic,1983; Hernández- } \\
\text { Espallardo et al., 2010) }\end{array}$ \\
\hline
\end{tabular}

Fonte: Desenvolvido pelos autores.

Já os elementos de governança são o meio de regular ou de influenciar comportamentos para atingir os objetivos planejados por uma organização (Storey et al., 2013). Os autores complementam que os elementos de governança formais são oriundos da teoria da agência e que os elementos informais são baseados na dinâmica das relações interorganizacionais.

Para Wallenburg et al. (2014), elementos de governança são proteções que as firmas utilizam para governar suas trocas interorganizacionais e, com isso, minimizar sua exposição ao oportunismo. Burkert et al. (2012) complementam o conceito de Wallenburg ao incluir proteção aos custos de transação e a promoção continuada de relacionamentos. Nesse sentido, o principal objetivo deste trabalho é analisar a relação entre as condições de troca e os elementos de governança. Entende-se que ambos os fatores estão contidos na relação diádica, existindo uma interação entre si. A Figura 1 representa o esquema de pesquisa que ilustra a visão geral deste trabalho.

Figura 1 - Esquema de pesquisa

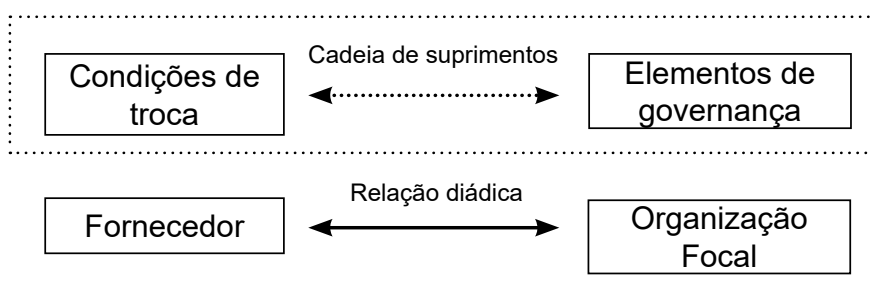

Fonte: Desenvolvido pelos autores

Conforme a Figura 1 ilustra, a utilização dos elementos de governança diante de condições de troca ocorre no ambiente da cadeia de suprimentos. Mas essa interação é peculiar em cada relação diádica. Por exemplo, risco é uma condição de troca que pode implicar em desabastecimento de materiais em uma relação 
diádica, mas também pode significar perigo à saúde das pessoas em outra. Em cada caso, o elemento de governança a ser utilizado pode ser diferente e, a partir disso, projeta-se a utilização de elementos de governança, explicada pelas condições de troca existentes nas relações diádicas.

\section{Procedimentos metodológicos}

A estratégia de pesquisa adotada é o estudo de caso único com unidades incorporadas. Essa condição é explicada porque se trata de uma organização focal, mas com múltiplas unidades de análise (YIN, 2001), representadas pelas relações diádicas da empresa com seus fornecedores. No que se refere ao objetivo, este estudo caracteriza-se como explanatório, porque visa explicar como tais decisões ocorrem na organização focal. Por consequência, define-se o método de pesquisa qualitativo para a realização deste trabalho.

A pesquisa empírica foi realizada na Hyundai Elevadores do Brasil Ltda. por tratar-se de um novo competidor no mercado brasileiro e que estava desenvolvendo sua cadeia de suprimentos na época da pesquisa. Ao todo, três tipos de relações diádicas foram avaliadas. A primeira relação diádica (RD1), identificada como Hyundai - W, ocorre entre a organização focal e seus fornecedores de materiais, como, por exemplo, chapas de aço e materiais elétricos. A segunda relação diádica (RD2), identificada como Hyundai $-S$, ocorre entre a organização focal e fornecedores de serviços corporativos. Planos de saúde e alimentação são exemplos desse tipo de serviço. A terceira relação diádica (RD3) é identificada como Hyundai - AE e associa a organização focal ao fornecedor de serviços de instalação.

O cuidado na escolha dos entrevistados é evidenciado por suas posições na estrutura organizacional de suas respectivas empresas, e também pelo vínculo direto com as relações diádicas que representam as unidades de análise deste estudo. Nesse sentido, sete foram os participantes de acordo com seus vínculos a cada tipo de relação diádica. Para a relação com os fornecedores de materiais, foi entrevistado o diretor comercial nomeado (DCW), os gestores das áreas de compras (GCH) e desenvolvimento (GDH) da Hyundai. Para a relação com fornecedores de serviços corporativos foi entrevistado o gestor da área de recursos humanos (GAH) da Hyundai e do fornecedor serviços corporativos foi o gestor de relacionamento (GRS). Por fim, para a relação com fornecedores de serviços de instalação, o gestor de instalações (GIH) da Hyundai e o proprietário (PAE) dos serviços de instalação foram os participantes.

Todas as entrevistas foram previamente agendadas com cada gestor, visando obter desse profissional o máximo de dedicação para o tema da entrevista. O local de realização das entrevistas propiciou ao respondente um ambiente neutro, isto é, fora do seu ambiente de trabalho. Dessa maneira, eventuais interrupções provocadas por situações de cotidiano foram evitadas. De modo a permitir o aproveitamento máximo das informações coletadas, as entrevistas foram gravadas entrevistas e a separação do material disponível permitiu a elaboração de três relatórios distintos, dedicados a cada tipo de relação diádica analisada. Durante o processo de coleta de dados, foi concedido o acesso e a análise de documentos, entre eles: contratos, e-mails e atas de reuniões, que evidenciam acordos de operação entre a Hyundai e seus fornecedores.

A coleta de dados foi realizada por meio de entrevistas em profundidade, com roteiro semiestruturado. A elaboração do roteiro semiestruturado foi baseada no instrumento utilizado por Dolci (2013). O autor sugere um modelo para avaliar a influência dos investimentos em tecnologia da informação ( $\mathrm{TI})$, na governança da cadeia de suprimentos e seu desempenho, abordando o tema da governança na cadeia de suprimentos, assim como os elementos utilizados pelas organizações para realizar esse processo. A validação de construto foi obtida por meio da submissão do instrumento de pesquisa à avaliação de dois especialistas no tema cadeia de suprimentos. Além disso, duas entrevistas-teste foram realizadas com gestores da organização focal antes do início da coleta de dados formal. Diante do bom nível das respostas obtidas nessa fase, não houve a necessidade de mudança no instrumento de pesquisa. Os dados coletados nesses testes foram descartados.

Para a análise dos dados, utilizou-se o método de análise de conteúdo (BARDIN, 2009). A razão dessa escolha está na sua forma, que exige a definição de regras de análise, a determinação de categorias para a interpretação dos dados e, afinal, os critérios de confiabilidade e validade (MAYRING, 2000). Portanto, a 
escolha da análise de conteúdo tem por objetivo proporcionar a esta pesquisa o estabelecimento do rigor científico almejado. Seguindo a análise de conteúdo, foram definidas como categorias analíticas as condições de troca e os elementos de governança discutidos na revisão de literatura, recuperados no Quadro 5.

Quadro 5 - Categorias e critérios da análise de conteúdo

\begin{tabular}{|c|c|c|}
\hline Categorias & Subcategorias & Critérios \\
\hline \multirow{3}{*}{ Condições de troca } & Oportunismo & \multirow{13}{*}{$\begin{array}{l}\text { Análise das respostas obtidas } \\
\text { Análise de documentos }\end{array}$} \\
\hline & Poder & \\
\hline & Risco & \\
\hline \multirow{7}{*}{ Elementos de governança } & Colaboração & \\
\hline & Confiança & \\
\hline & Contrato & \\
\hline & Controle & \\
\hline & Incentivo & \\
\hline & Motivação & \\
\hline & Relacionamento & \\
\hline \multirow{3}{*}{ Aplicação dos elementos de governança } & Oportunismo & \\
\hline & Poder & \\
\hline & Risco & \\
\hline
\end{tabular}

Fonte: Desenvolvido pelos autores.

\section{Apresentação e Análise dos Resultados}

\subsection{Oportunismo e os elementos de governança aplicados}

Os respondentes das RD1 e RD2 declararam que oportunismo é uma condição de troca ausente em suas respectivas relações. De maneira geral, todos associaram esse conceito a um comportamento indesejado. O oportunismo é avaliado sob a concepção de um ato de suborno ou corrupção, no qual o gestor declara não dispor de uma política clara, que defina o comportamento esperado pela organização para enfrentar situações dessa natureza.

Confiança foi um elemento de governança apontado na RD1 como aplicável sobre comportamentos oportunistas. Embora declarada como uma condição de troca ausente, o relato a seguir evidencia uma contradição:

Se for falar, até questão de compliance, a gente não sabe o que eu posso aceitar do fornecedor de brinde ou algo que pudesse ser enquadrada como oportunismo [...] Não existe uma regra bem definida para isso, vai do caráter de cada um (GDH).

A utilização de confiança pode ser entendida como o resultado da omissão na escolha de um elemento de governança diante de oportunismo. Aparentemente, tal indefinição conflita com a expectativa do GDH, que expressa a sua vontade de obter uma regra explícita, o que denota a influência dos preceitos da teoria da agência sob o seu modo de pensar.

O entrevistado GCH exemplifica a postura que pode ser adotada para se aproveitar uma oportunidade, esclarecendo suas intenções e construindo, assim, patamares de confiança para alcançar o objetivo que Ihe interessa. Sob essa forma de atuação, infere-se o alinhamento com a stewardship theory, porque existe a preocupação com a outra parte, o que é mais compatível com a relação líder-seguidor, do que o vínculo principal-agente (HERNANDEZ, 2007).

Controle foi outro elemento de governança elencado na RD1 para minimizar a possibilidade de oportunismo. A sua utilização é de nível operacional, visando assegurar a realização do acordo estabelecido entre a Hyundai e seus fornecedores, que se expressa através da verificação rotineira entre o que foi comprado 
e o que foi entregue. Conforme relato, o nível operacional de aplicação desse elemento de governança permite inferir a influência dos pressupostos da teoria da agência:

Pode ser o controle de entrega, o controle de qualidade, pode ser o controle de informação. É o ato de tu buscar uma forma a garantir que o que vocês forem falando, se comprometendo e se programando, aconteça $(\mathrm{GCH})$.

Na RD3, controle também é utilizado diante de oportunismo, sendo expresso em cláusula contratual. Todavia o relato do fornecedor de serviços de instalação (AE) revela a baixa incidência desse exemplo de controle, baseando-se em sua percepção sobre a restrição de recursos da Hyundai para desempenhar tal função.

Eu já entrei em obra, comecei e finalizei sem ninguém ter ido lá ver nada. Às vezes, eles vão lá e olham, mas é muito difícil. Como tem um coordenador só para atender toda a RS (região), é difícil ele conseguir dar atenção a todas as obras (PAE).

Contrato e relacionamento são outros elementos de governança identificados na RD3 em relação à condição de troca oportunismo. Infere-se que, nessa díade, há maior probabilidade de exposição ao comportamento oportunista dadas as evidências coletadas.

Por exemplo, a AE não executa o contrato, nós não executamos (AE), entendeu? Nós não cumprimos a nossa parte e eles não nos executam, e têm multas de ambos os lados $(\mathrm{GIH})$.

Neste relato se identifica o alinhamento com os pressupostos da stewardship theory na utilização dos elementos de governança, porque ocorre o envolvimento pessoal e disseminação de confiança por meio de relacionamento. Tais fatores exemplificam os mecanismos situacionais desenvolvidos por Davis, Schoorman e Donaldson (1997).

\subsection{Poder e os elementos de governança aplicados}

As três relações diádicas analisadas apontam a utilização de diferentes elementos de governança em situações de assimetria de poder. Na RD1, o poder é uma condição de troca de intensidade moderada. De acordo com o relato dos respondentes, a interação entre a Hyundai e a W é marcada, desde o início, por atividades colaborativas e um relacionamento bastante próximo, baseado em transparência e respeito mútuo. Diante de tal ambiente, a relação de poder entre as empresas se manteve equilibrado.

Na RD1 ocorre utilização de colaboração, que pode ser explicado pela maior interação que caracteriza a relação entre a Hyundai e o seu fornecedor de materiais, porque a atualização dos projetos de elevadores começa a partir dos componentes que são adquiridos desse grupo de fornecedores, representado, nesta pesquisa, por W. Conforme pode ser observado no relato:

A colaboração é justamente a palavra para reduzir essas diferenças de poder, ok? Quanto mais colaboração tu tiveres, essas diferenças de poder, elas devem ser menores (GCH).

Os contratos informais flexibilizam a governança do fornecedor de materiais, de modo a acompanhar as demandas do mercado de elevadores. Na RD1, esse elemento de governança é utilizado pela Hyundai para impor suas necessidades de fornecimento e, assim, fazer o uso do poder a seu favor. Isso é interessante para o fornecedor, porque lhe assegura a manutenção dos negócios com a Hyundai. A utilização de contratos informais é uma indicação da influência dos pressupostos da stewardship theory, porque, conforme Hernandez (2007), as trocas sociais viabilizam o atendimento de necessidades do líder (Hyundai) e do seguidor (W).

$\mathrm{Na} \mathrm{RD} 2$, a relação de poder entre a Hyundai e a S é inclinada na direção da empresa fornecedora. Nota-se que a S leva certa vantagem sobre a Hyundai, por ser uma organização melhor estruturada, com processos internos mais robustos. Nessa díade, nota-se alinhamento com os pressupostos da teoria da agência, que se expressa por meio do contrato formal, utilizado para manter o rigor no cumprimento dos acordos estabelecidos entre a Hyundai e seu fornecedor de serviços corporativos. 
De forma complementar, nota-se que a $S$ utiliza o relacionamento como um reforço para consolidar os acordos contratuais, de modo a intensificar o seu poder na relação com a Hyundai. Relacionamento é um elemento de governança característico da stewardship theory, o que é suportado pelo estudo do amparo relacional, desenvolvido por Hernandez (2007). O relato a seguir evidencia o uso do relacionamento na RD2:

A gente conversa abertamente e sempre tenta alinhar que seja bom para os dois. Até a S, por ser francesa, ela (a organização) não entende muitas coisas nossas, se está escrito em contrato, porque estão questionando? Sabe? Para eles, é uma coisa difícil, daí eu explico: 'brasileiro não é assim, o que está ali (contrato) não quer dizer que vai ser assim', a gente sabe que, com os nossos clientes, a gente tem que discutir. Chegar a um consenso com a Hyundai é tranquilo (GRS).

Em face à assimetria de poder, o controle é utilizado na RD2, evidenciando novamente o alinhamento com os pressupostos da teoria da agência. É com esse elemento de governança que a Hyundai consegue equilibrar a relação de poder com o seu fornecedor de serviços corporativos, conforme depoimento:

Quando acontece alguma reclamação, eu consigo dizer: 'isso não serve, nós fechamos baseado no que vocês disseram', na questão da qualidade e eu não estou enxergando isso' (GH).

O gestor aponta controle como o único elemento de governança capaz de permitir uma negociação frente ao contrato firmado com seu fornecedor.

$\mathrm{Na}$ RD3 os gestores mencionaram que, diante da assimetria de poder, não utilizam elementos de governança. O gestor da Hyundai menciona que não lhe foi atribuído poder, senão exigir do fornecedor de serviços de instalação o cumprimento dos termos dispostos em contrato. Já o proprietário da AE respondeu que é dependente da relação que sua empresa tem com a Hyundai. Por conta disso, nenhum elemento de governança é utilizado nessa relação diádica.

\subsection{Risco e os elementos de governança aplicados}

Risco é uma condição de troca presente nas três relações diádicas e todos os respondentes identificaram a utilização de elementos de governança. Contrato, controle e relacionamento são os elementos de governança comuns às três díades.

O contrato é utilizado de forma peculiar em cada uma das díades analisadas. Na RD1, os contratos informais são utilizados, aliados a relacionamento e colaboração, para auxiliar a governança de riscos, como a falta de materiais necessários à produção da Hyundai. O relato que segue justifica essa associação de elementos de governança, que é representada pela palavra parceria:

Eu posso usar o contrato como exemplo entre a W e nós, em que nós temos uma defasagem de poder, por eles serem exclusivos. Se eles inventarem de não fornecer, a gente está correndo um grande risco. O contrato é uma forma de tentar reduzir, mas não é garantia. Então, hoje em dia, a parceria faz com que eu tenha acesso para aproveitar e reduzir os riscos $(\mathrm{GCH})$.

$\mathrm{Na}$ RD2, o risco é mitigado por meio do contrato, o que se exemplifica pelas alterações no escopo dos serviços contratados entre a Hyundai e seu fornecedor de serviços corporativos. No entanto é o fornecedor que utiliza o contrato, auxiliado por controle como elementos de governança sobre tal risco, conforme relata:

Qualquer mudança de cardápio, 'agora nós vamos servir cento e cinquenta gramas de carne em vez de cento e vinte': vou fazer um aditivo. Até porque, a gente tem auditorias internas também, que vêm fiscalizar o contrato. 'Ah não, ali está palito sachê, palito sachê não está no contrato, tu não podes servir palito sachê' (GRS).

Finalmente, a utilização do contrato na RD3 visa proteger a Hyundai contra o risco de baixo desempenho do fornecedor de serviços de instalação: 
Por exemplo, o instalador, se eu tenho um histórico de performance dele, eu consigo analisar se contrato ou não, ou seja, se é um instalador ruim, eu não contrato $(G I H)$.

Nas três relações diádicas, o controle é um elemento de governança que visa mitigar riscos por meio de sistemas de monitoramento e que denota a influência da teoria da agência. Na RD1, processos formais de rotina minimizam o risco de desenvolver um fornecedor com problemas financeiros. Na RD2, o gestor da Hyundai afirma não perceber riscos, tamanha sua confiança nos procedimentos operacionais de seu fornecedor de serviços corporativos. Já na RD3, o gestor da Hyundai mantém um banco de dados com informações sobre os fornecedores de instalação para lhe apoiar na decisão de firmar novos contratos com um mesmo fornecedor.

Os três gestores da Hyundai apontam o relacionamento como um elemento de governança de alta importância diante de riscos. O relato que segue demonstra tal constatação:

Nós estamos atrasando uma obra, o cliente me ligou e disse: 'sexta-feira eu vou tirar o elevador de cremalheira da obra, o teu prazo é segunda-feira para me entregar o elevador e tu não vai me entregar'. Chamei o PAE: 'amigão, está acontecendo isso e isso, está na hora de tu provar para mim a confiança que eu tenho em ti. Eu te trouxe lá da outra, eu briguei por ti, então, assim ó, esse elevador tem que estar entregue para o cliente segunda-feira de manhã, faça o que tiver que fazer'. O instalador disse 'deixa comigo, eu vou virar noite aqui todos os dias para entregar esse elevador' e segundafeira estava entregue $(\mathrm{GIH})$.

Nas citações acima, destacam-se os resultados que podem ser obtidos quando esforços conjuntos são aplicados por meio de relacionamento. De acordo com o modelo proposto por Hernandez (2012), entre os fatores psicológicos que explicam o comportamento stewardship, encontra-se a busca por relacionamento que objetivam longo prazo e empatia.

Nas RD2 e RD3, o elemento de governança confiança é utilizado em face de riscos. Na RD2, a confiança que o gestor da Hyundai deposita nos procedimentos do fornecedor de serviços corporativos é suportada por processos organizacionais bem definidos. Por outro lado, os relatos dos entrevistados da RD3 podem exemplificar a melhor expressão de confiança mútua, ainda que esteja baseada mais na relação interpessoal do que na relação corporativa. Segue depoimento em consonância:

Sempre quando eu precisei de algo a mais, eu sempre corri mais para o $\mathrm{GIH}$, que foi sempre quem me ajudou mais, desde o início. Então, tudo que a gente fez, foi tudo conversando com ele, tentando se adequar mais (PAE).

A influência da stewardship theory é percebida pelo alinhamento com os estudos de Hernandez (2007), que estabelece a confiança como o resultado da interação entre o líder e seu seguidor nos níveis relacional, contextual e motivacional. O nível relacional é explicado pelo relacionamento interpessoal. $\mathrm{O}$ nível contextual pode ser o elo institucional entre as organizações, e o motivacional envolve a capacidade do líder em desenvolver o seguidor, que, nesse exemplo, refere-se ao fornecedor.

Somente na RD3 todos os sete elementos de governança são utilizados diante de riscos. Portanto, colaboração, incentivo e motivação são identificados nessa díade. Sem o exercício de colaboração, o fornecedor vai executar seu trabalho com dificuldade e seu pagamento pode atrasar em função disso. As ações motivacionais e a oferta de incentivos são elementos de governança que o gestor da Hyundai utiliza de forma pessoal, aparentemente por se sensibilizar com a dificuldade que é imposta ao seu fornecedor em âmbito corporativo, conforme relato:

Eu elogio quando tem que ser elogiado, ajudo, oriento. Orientar é um meio de motivar, não deixar o cara fazer errado. Então, eu vou à obra e digo: 'olha, cuida com isso aqui, é uma coisa que todo mundo erra, não comete esse erro'. Aí o cara se sente motivado, ele vê que eu estou cuidando, sabe? (GIH).

Nessas citações, identifica-se um comportamento compatível com os pressupostos da stewardship theory, na decisão do gestor em utilizar tais elementos de governança, porque o GIH reconhece que não 
será capaz de realizar um bom trabalho se não agir proativamente no desenvolvimento de seu fornecedor, seja em âmbito interpessoal, seja em nível motivacional. (HERNANDEZ, 2007).

Outros estudos apontam os mesmos elementos de governança aplicados em face de risco. Ao estudar a mitigação de riscos em cadeias de suprimentos globais, Arnold et al. (2012) identificam controle como elemento de governança e, entre seus resultados, revelam melhores níveis de relacionamento e colaboração entre os membros dessa cadeia. Tal estudo evidencia um encadeamento ao descrever que o controle gera redução de riscos, o que, por sua vez, abre espaço para outros dois elementos de governança. Comparativamente, essa descoberta se aproxima dos resultados obtidos neste estudo de caso pela ocorrência de associações entre mais de um elemento de governança.

O resultado da pesquisa realizada por Lee e Cavusgil (2006) aponta que nas alianças estratégicas, em que se utiliza o relacionamento como elemento de governança, há melhor desempenho do que nas alianças governadas por contratos, ainda que esses objetivem a redução de riscos. Tal vínculo na utilização de contrato e relacionamento é encontrado também na relação diádica entre a Hyundai e seu fornecedor de materiais.

A utilização conjunta de contrato e controle foi o foco de estudo de Selviaridis e Norrman (2014) ao analisar o risco de fornecedores de serviços ao firmarem contratos baseados em níveis de desempenho. Wiengarten et al. (2013) também pesquisaram esses dois elementos de governança utilizados diante de riscos no desempenho de terceirizações no setor industrial. Na relação entre a Hyundai e seu fornecedor de serviços corporativos também foi verificada a utilização integrada de contrato e controle sobre os riscos.

\subsection{Comparação entre as díades e implicações da pesquisa}

O Quadro 4 retoma a utilização dos elementos de governança diante das três condições de troca analisadas. Para o poder, as palavras equilíbrio e assimetria indicam o que ocorre nas três relações diádicas analisadas. Para o oportunismo e o risco, as palavras baixo, moderado e alto apontam o nível de exposição da relação diádica a cada condição de troca. Nessa representação gráfica, a utilização de um elemento de governança foi dimensionada pelas palavras forte e moderada. Essa noção de intensidade foi medida pelo número de menções de um elemento de governança. As células em branco identificam a ausência de elementos de governança.

Quadro 4 - Condições de troca e elementos de governança

\begin{tabular}{|c|c|c|c|c|c|c|c|c|c|}
\hline \multirow{3}{*}{$\begin{array}{l}\text { Elementos de } \\
\text { governança }\end{array}$} & \multicolumn{3}{|c|}{ Poder } & \multicolumn{3}{|c|}{ Oportunismo } & \multicolumn{3}{|c|}{ Risco } \\
\hline & RD1 & RD2 & RD3 & RD1 & RD2 & RD3 & RD1 & RD2 & RD3 \\
\hline & Equilíbrio & Assimetria & Assimetria & Baixo & Baixo & Alto & Moderado & Alto & Alto \\
\hline Colaboração & Forte & & & & & & & & Forte \\
\hline Confiança & & & & Moderada & & & & Forte & Moderada \\
\hline Contrato & Moderada & Forte & & & & Forte & Moderada & Forte & Forte \\
\hline Controle & & Forte & & Moderada & & Moderada & Moderada & Forte & Moderada \\
\hline Incentivo & & & & & & & & & Moderada \\
\hline Motivação & & & & & & & & & Moderada \\
\hline Relacionamento & & Forte & & & & Forte & Forte & Forte & Forte \\
\hline
\end{tabular}

Fonte: Desenvolvido pelos autores.

O reconhecimento de diferentes condições de troca em cada relação diádica é uma primeira explicação para a utilização de elementos de governança em cadeias de suprimentos. Risco e poder são condições de troca presentes nas três díades analisadas. Já o oportunismo é percebido somente na RD3. Essa diferença é relevante porque, na ausência de uma condição de troca, a utilização de elementos de governança pode ser desnecessária. 
Ambos os gestores da RD3 relatam não utilizar elementos de governança diante da condição de troca de poder. Tal descoberta permite inferir que a utilização de elementos de governança, ainda que imprescindível, é dependente de uma decisão e, por isso, facultativa. A ausência ou demora nessa tomada de decisão pode ampliar o impacto de problemas em uma relação diádica ou, ainda, provocar outras consequências.

Em outros estudos (WALLENBURG et al., 2014; STOREY et al. 2013; WIENGARTEN et al., 2013), nota-se maior ênfase em analisar comparações entre os diferentes elementos de governança utilizados, além de pouco interesse em investigar a decisão que antecede tal utilização. Por exemplo, Huang et al. (2012) explicam que, em face à assimetria de poder e ao oportunismo, as organizações utilizam elementos de governança complementares em suas cadeias de suprimentos, tais como o controle formal e o controle social.

Outro ponto importante é a diferença nas origens de cada condição de troca entre as relações diádicas. As fontes de poder são diferentes, os motivos que justificam o comportamento oportunista são variados e os riscos contidos em cada díade não são os mesmos. Enquanto o maior risco na RD1 é a falta de abastecimento de materiais, a RD2 preocupa-se com a qualidade da alimentação das pessoas e, na RD3, o atraso na entrega do elevador é um risco constante. Tal diferença resulta na utilização de elementos de governança distintos em cada caso, ainda que compatíveis com a peculiaridade de cada situação. Dessa forma, entende-se que cada condição de troca tem origens diferentes, o que explica a utilização de um ou outro elemento de governança.

Essa resposta ao problema de pesquisa alinha-se com o estudo de Ness e Haugland (2005) sobre a evolução de elementos de governança e estratégias de negociação nos relacionamentos interorganizacionais. Os autores argumentam que a governança de diferentes situações na cadeia de suprimentos requer diferentes elementos. Além disso, complementam que a atuação de uma condição de troca específica pode ser resolvida com a utilização de múltiplos elementos de governança.

Outra explicação razoável é a influência pessoal dos gestores sobre as decisões organizacionais. A exposição a uma condição de troca, como oportunismo, gera reações variadas. Na RD1, o fornecedor evita manter relacionamento sob tal condição de troca e assim se protege. Na RD3, o oportunismo é contido pela utilização de controles, e, na RD2, o oportunismo não é percebido, o que pode ser um posicionamento pessoal discreto diante de um comportamento adverso. Em resumo, as condições de troca explicam a utilização de elementos de governança por meio da pessoalidade, que interfere no processo decisório dos gestores envolvidos na cadeia de suprimentos. Essa resposta ao problema de pesquisa se alinha com o estudo de Ghoshal (2005), que declara a influência da visão econômica sobre o comportamento humano individual e oportunista.

As condições de troca são fatores que geram incerteza ou exposição desfavorável sobre as relações diádicas. A recuperação do conceito de Poppo e Zenger (2002) é relevante para evidenciar que cabe aos integrantes da relação diádica a atuação sobre tais fatores. Além disso, vários autores descrevem a cadeia de suprimentos como uma rede orientada para objetivos de ordem comum (COX, SANDERSON E WATSON, 2001; HEARNSHAW, 2013). Diante de tais conceitos, a relação diádica pode ser entendida não apenas como a interação entre fornecedor e cliente, mas também como uma unidade que orienta as capacidades das duas organizações em prol de objetivos comuns, o que significa que as organizações se unem para atuarem juntas diante das condições de troca.

$\mathrm{Na}$ análise da RD1, a utilização de colaboração, confiança e relacionamento denotam um alinhamento estratégico que se assemelha à orientação para objetivos comuns. Na RD2, a confiança que o gestor da Hyundai declara ter no seu fornecedor atribui a essa díade uma característica difícil de ser construída e que, provavelmente, será protegida pelas duas organizações. A análise da RD3 demonstra que o relacionamento entre o gestor da Hyundai e seu fornecedor é capaz de realizações que ultrapassam os limites do contrato formal firmado pelas empresas. Tais casos exemplificam essa potencialidade da relação diádica de fazer ambas as organizações atuarem em conjunto.

As condições de troca explicam a utilização dos elementos de governança, porque são formadas por fatores indesejados na relação diádica, ainda que provoquem vantagem para uma das partes, como a 
assimetria de poder. Diante de tais fatores, compete à díade reunir esforços conjuntos, o que culmina na decisão de utilização dos elementos de governança.

\section{Considerações Finais}

Os dados analisados apresentam evidências de que a utilização de elementos de governança sobre a cadeia de suprimentos é um exercício de escolha, por isso, é suscetível ao viés pessoal. Dentre os elementos de governança estudados, colaboração, confiança, motivação e relacionamento são conceitos que, para serem praticados, exigem relações interpessoais. Tal inferência é reforçada pelos pesquisadores da stewardship theory, que reúnem esses quatro conceitos para exemplificar os pressupostos dessa teoria.

Entre outros conceitos, colaboração, confiança e relacionamento formam os fatores estruturais e psicológicos que definem o comportamento stewardship. Entre os relatos dos gestores entrevistados, vários exemplos analisados demonstram a interferência pessoal no processo de escolha de elementos de governança. Nesse sentido, a principal contribuição teórica deste estudo consiste em demonstrar que a governança de relações diádicas na cadeia de suprimentos pode ser influenciada pelo perfil dos gestores, a partir das condições de troca estabelecidas. Esse resultado contribui para os estudos de Lambert e Enz (2017) e Dolci, Maçada e Grant (2015) a respeito da governança da cadeia de suprimentos e estão alinhados aos pressupostos da stewardship theory.

Por outro lado, é provável que a ausência de uma diretriz corporativa permita o desenvolvimento de elementos de governança de ordem pessoal. Diante de tal ausência, não há referência capaz de apurar alinhamento com a orientação da organização, o que reforça essa proposta de contribuição teórica. Como contribuição gerencial, este estudo aponta a relevância de que as organizações criem uma diretriz corporativa para a forma de relacionamento esperado com seus fornecedores. Embora, em algumas situações, o perfil dos gestores possa influenciar corretamente a escolha de elementos de governança, isso fará com que a organização fique dependente da decisão pessoal dos gestores, e não de uma política corporativa planejada.

Portanto, esse estudo apresenta, como implicação gerencial, a utilização de elementos de governança como ferramentas de aplicação nos níveis estratégico (por meio da implementação de uma diretriz corporativa), tático (ao possibilitar a montagem de planos para a gestão de grupos de fornecedores com perfis específicos) e operacional, se tais ferramentas forem aplicadas no manejo de rotina das relações diádicas.

Como possibilidade de estudos futuros, sugere-se o desenvolvimento de uma pesquisa quantitativa que avalie de maneira mais ampla a incidência dos elementos de governança diante das condições de troca estudadas. Uma segunda proposta é a realização de uma pesquisa qualitativa mais aprofundada sobre um menor número de elementos de governança. Um estudo sobre a utilização de contratos e confiança como elementos de governança em cadeias de suprimentos, por exemplo. Tal proposta permitiria o desenvolvimento de trabalhos robustos, dada a relevância e contemporaneidade deste tema, o que é justificado pelo volume de estudos recentes disponíveis nas bases de dados científicos.

\section{Referências}

ARNOLD, Vicky; BENFORD, Tanya. S.; HAMPTON, Clark; SUTTON, Steve G. Enterprise Risk Management as a Strategic Governance Mechanism in B2B-Enabled Transnational Supply Chains. Journal of Information Systems, v. 26, n. 1, p. 51-76. 2012.

BENTON, W.C.; MALONI, Michael. The influence of power driven buyer/seller relationship on supply chain satisfaction. Journal of Operations Management, v.23, n. 1, p. 1-22, 2005.

BURKERT, Michael; IVENS, Björn Sven; SHAN, Jialu. Governance mechanisms in domestic and international buyer-supplier relationships: An empirical study. Industrial Marketing Management, v. 41, n. 3, p. 544-556, 2012.

COX, Andrew; SANDERSON, Joe; WATSON, Glyn. Supply Chains and Power Regimes: Toward an Analytic Framework for Managing Extended Networks of Buyer and Supplier Relationships. The Journal of Supply Chain Management, v. 37, n. 2, p. 28-35, 2001. 
DAVIS, James H.; SCHOORMAN, F. David; DONALDSON, Lex. Toward a Stewardship theory of management. Academy of Management Review, v. 22, n. 1, p. 20, 1997.

Defee, Clifford C.; Esper, Terry; Mollenkopf, Diane. Leveraging closed-loop orientation and leadership for environmental sustainability. Supply Chain Management: an International Journal, v. 14, n. 2, p. 8798, 2009.

DOLCI, Pietro. Modelo para avaliar a influência dos investimentos em TI na governança da cadeia de suprimentos e o seu desempenho. 2013. 239 f. Tese (Doutorado em Administração) - Escola de Administração. Universidade Federal do Rio Grande do Sul. Porto Alegre, 2013.

DOLCl, Pietro; Maçada Antonio; Grant Gerald. Exploring information technology and supply chain governance: Case studies in two brazilian supply chains. Journal of Global Information Management, v. 23, n. 3, p. 72-91, 2015.

Dyer, Jeffrey H. Specialized supplier networks as a source of competitive advantage: Evidence from the auto industry. Strategic Management Journal, v.17, n. 4, p. 271-291, 1996

EISENHARDT, Kathleen M. Agency Theory: An Assessment and Review. The Academy of Management Review, v. 14, n. 1, p. 57-74, 1989.

GHOSHAL, Sumantra. Bad Management Theories Are Destroying Good Management Practices. Academy of Management Learning Education, v. 4, n. 1, p. 75-91, 2005.

HEIDE, Jan B.; KUMAR, Alok; WATHNE, Kenneth H. Concurrent sourcing, governance mechanisms, and performance outcomes in industrial value chains. Strategic Management Journal, v. 35, n. 8, p. 1164-1185, 2013.

HEARNSHAW, Edward J. S.; WILSON, Mark. A complex network approach to supply chain network theory. International Journal of Operations Production Management, v. 33, n.4, p. 442-469, 2013.

HERNANDEZ, Morela. Promoting Stewardship Behavior in Organizations: A Leadership Model. Journal of Business Ethics, v. 80, n. 1, p. 121-128, 2007.

HERNANDEZ, Morela. Toward an Understanding of the Psychology of Stewardship. Academy of Management Review, v. 37, n. 2, p. 172-193, 2012.

HIRSCH, Paul; MICHAELS, Stuart; FRIEDMAN, Ray. "Dirty hands" versus "clean models". Theory and Society, v. 16, n. 3, p. 317-336, 1987.

HUANG, Ming-Chang; CHENG, Hsiang-Lin; TSENG, Chun-Yen. Reexamining the direct and interactive effects of governance mechanisms upon buyer-supplier cooperative performance. Industrial Marketing Management, v.43, n. 4, p. 704-716, 2014.

HUO, Baofeng; ZHAO, Xiande; LAI, Fujun. Supply chain quality integration: Antecedents and consequences. IEEE Transactions on Engineering Management, v. 61, n. 1, p. 38-51, 2014.

JENSEN, Michael C.; MECKLING, William H. Theory of the firm: Managerial behavior, agency costs, and ownership structure. Journal of Financial Economics, v. 3, p. 305-360, 1976

LAMBERT, D. M.; ENZ, M. G. Issues in Supply Chain Management: Progress and potential. Industrial Marketing Management, v. 62, p. 1-16, 2017.

LEE, Yikuan; CAVUSGIL, S. Tamer. Enhancing alliance performance: The effects of contractual-based versus relational-based governance. Journal of Business Research, v. 59, n.8, p. 896-905, 2006.

LUO, Yadong; LIU, Yi; ZHANG, Leinan; HUANG, Ying. A taxonomy of control mechanisms and effects on channel cooperation in China. Journal of the Academy of Marketing Science, v. 39, n.2, p. 307-326, 2010.

MORGAN, Neil A.; KALEKA, Anna; GOONER, Richard A. Focal supplier opportunism in supermarket retailer category management. Journal of Operations Management, v. 25, n. 2, p. 512-527, 2007.

MAYRING, Philipp. Qualitative Content Analysis, Forum: Qualitative Social Research, v.1, n.2, 2000. 
MÜLLER, Martin; GAUDIG, Sonja. An empirical investigation of antecedents to information exchange in supply chains. International Journal of Production Research, v. 49, n.6, p. 1531-1555, 2011.

NESS, Havard; HAUGLAND, Sven A.; The evolution of governance mechanism and negotiation strategies in fixed-duration interfirm relationship. Journal of Business Research, v. 58, n. 9, p 12261239, 2005.

NEWTON, Peter; AGRAWAL, Arun; WOLLENBERG, Lini. Enhancing the sustainability of commodity supply chains in tropical forest and agricultural landscapes. Global Environmental Change, v. 23, n.6, p. 1761-1772, 2013.

POPPO, Laura; ZENGER, Todd. Do formal contracts and relational governance function as substitutes or complements? Strategic Management Journal, v. 23, p. 707-725, 2002.

PROVAN, Keith G.; KENIS, Patrick. Modes of Network Governance: Structure, Management, and Effectiveness. Journal of Public Administration Research and Theory, v. 18, n.2, p. 229-252, 2007.

SELVIARIDIS, Kostas; NORRMAN, Andreas. Performance-based contracting in service supply chains: a service provider risk perspective. Supply Chain Management: an International Journal, v. 19, n. 2, p. 153-172, 2014.

STOREY, Chris; KOCABASOGLU-HILLMER, Canan. Making partner relationship management systems work: The role of partnership governance mechanisms. Industrial Marketing Management, v. 42, n.6, p. 862-871, 2013.

TEIXEIRA, Rafael; LACERDA, Daniel Pacheco. Gestão da cadeia de suprimentos: análise dos artigos publicados em alguns periódicos acadêmicos entre os anos de 2004 e 2006. Gestão e Produção, v. 17, n. 1, p. 207-227, 2010.

THOMÉ, Antonio Marcio T.; SCAVARDA, Luiz Felipe; PIRES, Silvio; CERYNO, Paula; KLINGEBIEL, Katja. A multi-tier study on supply chain flexibility in the automotive industry. International Journal of Production Economics, v. 158, n. 91-105, 2014.

VOSSELMAN, Ed; MEER-KOOISTRA, Jetlje Van Der. Accounting for control and trust building in interfirm transactional relationships. Accounting, Organizations and Society, v. 34, n. 2, p. 267-283, 2009.

WALLENBURG, Carl Marcus; SCHÄFFLER, Thorsten. The interplay of relational governance and formal control in horizontal alliances: A social contract perspective. Journal of Supply Chain Management, v. 50, n. 2, p. 41-58, 2014

WATHNE, Kenneth H.; HEIDE, Jan B. Relationship Governance in a Supply Chain Network. Journal of Marketing, v. 68, n. 1, p. 73-89, 2004.

WIENGARTEN, Frank; PAGELL, Mark; FYNES, Brian. The importance of contextual factors in the success of outsourcing contracts in the supply chain environment: the role of risk and complementary practices. Supply Chain Management: an International Journal, v. 18, n. 6, p. 630-643, 2013.

WILLIAMSON, O. E. Markets and hierarchies: antitrust analysis and implications, 1975.

YIN, Robert K. Estudo de caso: planejamento e métodos. 2. ed. Porto Alegre: Bookman, 2001

ZANDER Sebastian; TRANG Simon; KOLBE Lutz M. Drivers of network governance: a multitheoretic perspective with insights from case studies in the german wood industry. JournalofCleanerProduction, v. 110, n. 1, p. 109-120, 2016.

Submetido em: 09/10/2018

Aprovado em: 11/12/2019 